\section{NOVA TELLVS}

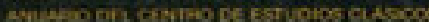

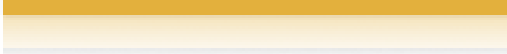

CHUAQUI, Carmen

Ecos de la dramaturgia griega

Nova Tellus, vol. 24, núm. 2, 2006, pp. 197-218

Centro de Estudios Clásicos

Distrito Federal, México

Disponible en: http://www.redalyc.org/articulo.oa?id=59120913008

- Cómo citar el artículo

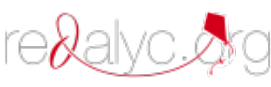

- Número completo

- Más información del artículo

Sistema de Información Científica

- Página de la revista en redalyc.org

Red de Revistas Científicas de América Latina, el Caribe, España y Portugal

Proyecto académico sin fines de lucro, desarrollado bajo la iniciativa de acceso abierto 


\title{
Ecos de la dramaturgia griega
}

\author{
Carmen Chuaqui \\ Universidad Nacional Autónoma de México
}

RESUMEN: En la llamada "cultura occidental”, son múltiples los estudios sobre la dramaturgia griega, como son numerosas también las obras que, durante siglos, la han recreado e imitado a través de la poesía, la novela, el teatro y la música. En este ensayo encontraremos el eco del teatro heleno en zonas periféricas al terreno tradicional, acotado por la filología eurocentrista, para mostrar que, fuera de éste, la dramaturgia griega también ha tenido resonancia.

$$
* * *
$$

ABSTRACT: In the so-called "Occidental culture", there are many works on Greek drama, as many are also the works that, for centuries, have recreated and imitated it through poetry, novel, theatre and music. In this essay, we will find the echo of Hellenic theatre in peripheral zones to the traditional area, marked by eurocentrist philology, to prove that, outside such an area, Greek drama has also had a resonance.

PALABRAS ClAVE: dramaturgia griega, eco, literatura bizantina, griego moderno. RECEPCIÓN: 13 de septiembre de 2006.

ACEPTACIÓN: 11 de octubre de 2006. 



\title{
Ecos de la dramaturgia griega
}

\author{
Carmen Chuaqui
}

Toda cultura que haya alcanzado cierto grado de madurez cuenta con un grupo de artistas a quienes considera "sus clásicos". Las culturas de una gran antigüedad — como la chinapueden darse el lujo de tener distintas épocas de florecimiento artístico. Uno de los rasgos característicos de la condición de "clásicos" es que las obras consagradas fueron capaces de trasponer los límites de la cultura en la cual surgieron. En el campo de la literatura ocupan un lugar destacado la dramaturgia griega, El Quijote de Cervantes y los dramas de Shakespeare, cuyos ecos siguen resonando al paso de los siglos en muy diferentes culturas.

No me detendré aquí a considerar la influencia que la literatura griega ha tenido en la llamada "cultura occidental" (entendida casi siempre como la producida en Europa occidental y Estados Unidos); para ello tenemos estudios magníficos como, por ejemplo, el panorámico de Gilbert Highet, La tradición clásica, ${ }^{1}$ o el de un caso particular, presentado por George Steiner en su Antígonas, ${ }^{2}$ donde el conflicto representado por Antígona y Creonte se transforma y reaviva en el teatro, la filosofía, la música, etcétera. Prefiero ocuparme en este ensayo de algunos ecos que ha tenido la dramaturgia griega en zonas

\footnotetext{
${ }^{1}$ Oxford University Press, 1949. En español: México, Fondo de Cultura Económica, 1954, con una excelente traducción de Antonio Alatorre.

${ }^{2}$ Ed. Georges Rorchardt, New York, 1984. En español: Barcelona, Editorial Gedisa, 1991.
} 
periféricas de la cultura europea, que se considera a sí misma receptora directa del legado greco-romano.

La primera zona que deseo explorar es, por paradójico que parezca, la propia cultura griega, pero en su desarrollo bizantino y moderno. La filología eurooccidental ha estudiado con loable rigor la época clásica y, después, la helenística, que resulta indispensable por ser el vehículo que permitió a los romanos conocer la antigüedad helena. De la época bizantina se rescata a los filólogos que conservaron y transmitieron los textos de sus antepasados, en tanto que a la Grecia moderna a menudo se la ve con indiferencia, cuando no con desprecio. Pero puede resultar muy provechoso estudiar la historia total de Grecia como un conjunto y adentrarse en su vasta literatura como un arte expresado en una lengua con cuatro mil años de existencia.

En la época helenística y romana se construyeron gran cantidad de hermosos teatros — desde Asia Menor hasta Españapero la tragedia griega, como género, fue desapareciendo paulatinamente. Si bien en un principio se representaban obras clásicas, después sólo se escenificaban pasajes selectos, aunque los temas dramáticos pervivieron en el gusto del público, pues eran continuamente empleados en la poesía y también parodiados en las muy populares escenificaciones cómicas. En el Imperio romano de Oriente la tragedia acabó por extinguirse; por una parte porque los espectáculos circenses del Hipódromo estragaron el gusto del público y, por otra, debido a que la Iglesia ortodoxa hacía cuanto le era posible por borrar las huellas del paganismo. Podemos fijar su fecha de muerte en el año 691, cuando en el segundo sínodo de Trullo se prohibió a los cristianos asistir a representaciones teatrales. Así, con el tiempo la palabra tragedia pasó a designar cualquier tipo de canto. ${ }^{3}$ La Iglesia compensó la afición griega por

\footnotetext{
${ }^{3}$ Cf. Montelatici, G., Storia della letteratura bizantina, Milano, Hoepli (Cisalpino-Goliárdica), 1976, pp. 37-41 y 137-138.
} 
las narraciones dialogadas permitiendo en los templos la representación de dramas litúrgicos, como el Simposio de las vírgenes de Metodio. Los filólogos alejandrinos tomaron la nefasta decisión de emplear en sus obras una lengua que intentaba conservar la de la época clásica; pero ya en la época bizantina el alejamiento entre la lengua culta y la popular era tal que la literatura se dividió en dos vertientes. Los dramas litúrgicos estaban escritos en la lengua vernácula, a fin de que el pueblo se instruyera a través de ellos.

Una vez que el Imperio logró recuperarse de la traumática irrupción del islam y de la pérdida de buena parte de su territorio, surgió el llamado "Renacimiento macedonio", durante el cual los estudiosos se dedicaron con gran entusiasmo a recuperar su pasado clásico y helenístico. La Iglesia, ya absolutamente arraigada, no puso reparos a la escritura de dramas litúrgicos en lengua clasicista. Así tenemos obras como la de Ignacio Diácono (s. IX), donde dialogan Dios, Adán, Eva y la

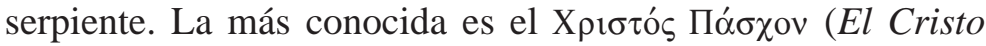
sufriente, generalmente traducido como La Pasión de Cristo), antes atribuida a Gregorio de Nazianzo, pero que es de un autor desconocido de fines del s. XI. Lo peculiar de esta obra (destinada a la lectura y no a la representación) es que se trata de un centón (o collage) de fragmentos de Eurípides, Esquilo, Licofrón y otros dramaturgos desconocidos; la mayoría son del primero y suponen un profundo conocimiento de por lo menos siete tragedias (Hécuba, Medea, Orestes, Hipólito, Troyanas, Bacantes y Reso).

El personaje principal es la Virgen. En un pasaje, el Teólogo sostiene el cuerpo de Cristo recién bajado de la cruz y se lo entrega a su madre. Para componer esta escena el autor se vale de Las bacantes de Eurípides: Ágave regresa a Tebas proveniente de las montañas del Citerón, con un tirso en la mano en el cual ha clavado la cabeza de su hijo Penteo (creyendo que es la de un león); poco después llega su padre, Cadmo, quien ha recogido el cadáver desmembrado de su 
nieto. Cadmo dialoga con su hija a fin de que salga del delirio inducido por Dioniso. Finalmente lo logra y Ágave va tomando en sus manos los restos de Penteo (vv. 1168-1300); sin embargo, en la obra faltan los versos que describen a la madre ante los despojos del hijo al que ha dado muerte. La reconstrucción de esta escena capital se ha hecho basándose precisa-

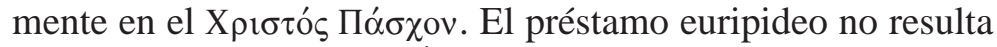
del todo adecuado, pues Ágave va tomando en sus manos los diferentes miembros, en tanto que la Virgen debe sostener en sus brazos el cuerpo íntegro de Cristo, y sabe muy bien quién es éste. En griego, el vocablo $\chi$ cíp significa tanto mano como brazo, pero aquellos traductores que hacen pronunciar a la Virgen "Oh mísera mano, recibe al muerto", deberían poner "brazos". Ágave debió haber dicho: "¿Qué cosa tengo entre las manos?", en referencia a la cabeza de Penteo, pero en labios de la Virgen resulta bastante absurdo. Este es el inicio del parlamento (vv. 1310-1325):

Virgen: Oh míseros brazos míos, reciban al muerto. Ay, ay, ¿qué estoy mirando? ¿Qué cosa tengo entre las manos? ¿Quién es éste, cuyo cadáver sostengo? ¿Cómo podré, desventurada, acercarlo con veneración a mi pecho? ¿Cómo lloraré? Hijo mío, concédeme que te hable como a un muerto y pueda besar cada uno de tus miembros. Permite a tu madre que bese tu diestra. Oh queridísima mano, que tantas veces yo sostuve y se prendía de mi mano como la hiedra a las ramas de la encina. Oh rostro amado, boca queridísima y noble cuerpo del hijo. ¡El tiernísimo contacto de tus labios! ¡La divina piel y el aliento dulcísimo del hijo, fragancia divina! ${ }^{4}$

Este drama litúrgico, como era de esperarse, no tiene mucho valor literario; no obstante, es un buen ejemplo de la vigencia

\footnotetext{
${ }^{4}$ En Cantarella, R., Poeti bizantini, Milano, Società Editrice "Vita e pensiero", 1948, vol. I, texto griego, p. 169, vol. II., trad. y notas, pp. 199 y 200 . Ver la edición crítica de Tuilier, A., La passion du Christ. Tragédie, Paris, Éditions du Cerf (Collection Sources Chrétiennes, 149), 1969.
} 
que todavía tenían los temas clásicos en un público bastante amplio.

Tras cuatro siglos de dominio otomano, Grecia logró su independencia, pero le llevó varias décadas liberar totalmente su actual territorio y cohesionar su vida. Un hito en el resurgimiento cultural fue la representación de obras del teatro griego clásico. La primera en subir a escena fue la Alcestes de Eurípides, en 1901. Hubiera sido imposible montar las antiguas tragedias en su lengua original, pues sólo un puñado de filólogos las hubiese comprendido; por ello se procedió a verter los textos a la dimotikí, es decir, a la lengua popular (a pesar de la profunda indignación que causó entre los partidarios de continuar empleando la lengua culta bizantina). Fue un gran acierto haberlo hecho, pues hoy en día se celebran todos los años ciclos de teatro griego que, ante un enorme público de griegos y extranjeros, llena como antaño las graderías del anfiteatro de Epidauro.

En Grecia no faltaron dramaturgos deseosos de "poner vino nuevo en odres viejos". Uno de ellos fue Níkos Kazantzákis (1883-1957), ese polígrafo cretense más conocido entre nosotros por sus novelas, como Zorba el griego, que por su labor como poeta, ensayista o traductor. Escribió dos dramas de tema clásico, Teseo y Prometeo, de poca relevancia; sin embargo, logra crear una verdadera tragedia a la manera clásica con un tema bizantino en su Konstantínos Poleológos, que fuera estrenada en Atenas en 1962. ${ }^{5}$ El protagonista es Constantino XI, el último emperador del Imperio bizantino, y la obra transcurre entre el 28 y el 29 de mayo de 1453, es decir, en la víspera de que Constantinopla, "la ciudad reina", sucumba ante el ejército turco.

Como es bien sabido, los dramaturgos griegos de la época clásica basaban sus tramas en la épica y la mitología, en tanto

\footnotetext{
${ }^{5}$ La única traducción al español que conozco es la de Miguel Castillo Didier, en la Editora Santiago, Chile, 1967, la cual seguramente ha de estar fuera del mercado.
} 
que su público no esperaba relatos nuevos, sino novedosas maneras de narrar tramas antiguas. Cuando Frínico presentó un acontecimiento contemporáneo, la toma de Mileto, causó tal conmoción en los espectadores la representación de la reciente pérdida de esa ciudad del Asia Menor, en manos de los persas, que las autoridades prohibieron ese tipo de temas, pues en vez de producir catarsis, sólo provocaba angustia. Lo que hace Kazantzákis es una mezcla de las dos perspectivas: por una parte presenta una trama que todos los griegos conocen, pero que no es ficción, sino historia real, aun cuando lo suficientemente alejada en el tiempo como para permitir el necesario distanciamiento emocional.

El autor pone en escena el conflicto interno que hizo aún más difícil la defensa de la capital, debido a la diversidad de intereses. Los protagonistas reales/ficticios son:

1. El emperador Constantino. A pesar de que en la realidad su gobierno (iniciado en 1449) fue acertado, ni el pueblo ni parte de la iglesia lo apoyaban, debido a problemas iniciados por su padre: el emperador Manuel II había emprendido un largo viaje por Europa para solicitar la ayuda de los odiados "francos". Por otra parte, su hermano, el emperador Juan VIII, firmó en 1439 un tratado con el Papa Nicolás en el que se unían la iglesia romana y la ortodoxa e, implícitamente, ésta quedaba subordinada a la primera. Constantino, quien esperaba con ansia la llegada del ejército latino, permite que en 1452 se celebre en Santa Sofía una misa según el rito romano.

2. Miembros DE LA IGLesia. Algunos obispos eran "unionistas", pero gran cantidad de sacerdotes y monjes estaban en contra. En la obra aparecen como representantes de la iglesia un cardenal unionista y un higúmeno (lit. "conductor", el superior de un monasterio), un ortodoxo a ultranza dispuesto a destronar al emperador. Tras este personaje está el filósofo Giórgos Scolários, quien estaba contra la unión y se hizo 
monje para combatirla; más tarde se convertirá en Gennadios II, el primer patriarca bajo gobierno otomano.

3. Aristócratas. Como respresentante de la nobleza bizantina aparece Notarás, un personaje real: el gran duque Lucas Notarás, hombre de gran riqueza e influencia, casado con una Paleólogo, y que pronunciara la famosa frase: "es preferible el turbante del sultán que el capelo de un cardenal". A pesar de que muchos nobles estaban más preocupados por conservar sus privilegios que por defenderse de turcos o latinos, el vedardadero Notarás luchó con denuedo en las murallas de la ciudad. Aparece también un tal Franzís, gran amigo de Constantino (a la manera de Orestes y Pílades), quien en vida fue Giórgos Sfrantzês, secretario de Manuel II y que evaluó para Constantino las fuerzas combatientes (cinco mil griegos y dos o tres mil mercenarios, es decir, que lucharon en una relación de diez a uno entre turcos y bizantinos); cayó prisionero en la toma de Constantinopla y, más tarde, fue uno de los principales historiadores de la caída del Imperio.

4. Latinos. En suelo griego quedaban aún familias de nobles de los ya casi extintos reinos latinos (Constantino estaba casado con una mujer latina). En la obra aparece otro personaje real, Giustiniani, un genovés que aportó a la batalla dos navíos y setecientos hombres. Los genoveses y algunos venecianos que lucharon al lado de los griegos no fueron enviados por ningún país latino; estaban ahí protegiendo sus intereses, pues por siglos comerciaron en tierras bizantinas. En el tercer acto el autor incluye una pequeña escena romántica: aparece en la muralla Ana, la hija de Notarás, acompañada de una nodriza, en busca de su amante, nada menos que Giustiniani; la escena recuerda, por supuesto, a Helena y Príamo en las murallas de Troya (de la Ilíada) y a Antígona y su pedagogo en las de Tebas (de Las fenicias de Eurípides). Ana le pide una última noche de amor, pero él - como era de esperarse - antepone su deber de soldado y la obliga a marcharse. 
5. Mensajeros. Como ninguna tragedia griega puede prescindir del personaje que trae noticias del exterior, en la obra hay tres mensajeros. Franzís funciona como tal al informar al emperador sobre el estado de las tropas y como embajador ante el higúmeno para tratar de hacer las paces. En el segundo acto, Constantino dice que el valiente capitán cretense Jarkutsis "traerá la noticia de que ya aparecieron las fragatas cristianas", aun cuando en el acto cuarto el capitán informará que no hay ni habrá socorro alguno y se unirá a la pelea. (Hay que perdonar este rasgo de nacionalismo del autor, pero la obra fue escrita durante la ocupación de las fuerzas nazis en Grecia, y los cretenses se defendieron con gran heroísmo.) En el segundo acto llega a la corte un enviado del sultán, quien propone a Constantino que se rinda y, a cambio, le concederá "el Despotado de Mistrá [gobernado por los Paleólogo], a fin de que, como soberano, alegre el resto de su vida". Como el emperador se negara, el mensajero le dice que un gran amigo suyo, el Gran Visir, sabe que al amanecer será asaltada la ciudad y lo insta a que huya. Constantino, a pesar de que tanto los representantes de los nobles como los del pueblo le piden que acepte, rechaza ambas propuestas y opta por su destino: morir por la ciudad.

6. El pueblo. Aunque el autor no lo especifica, el pueblo bizantino hace las veces del coro y, en una escena, las madres de los soldados hacen otro tanto. En sus respectivas intervenciones expresan su desesperación por las penurias que padecen y el miedo ante la inminente derrota.

El escenario de los cuatro actos es: 1) la gran plaza frente al palacio, donde el pueblo se congrega; 2) la sala del trono, en la que los notables discuten sus posiciones; 3 ) un torreón cercano a la puerta Romanós, donde Constantino librará su última batalla ante las huestes de Mehmet II, y 4) la iglesia de Santa Sofía, en la cual se refugian los sobrevivientes en espe- 
ra de un milagro o de la rendición. Así como en las obras antiguas la voluntad de los dioses es omnipresente, en ésta todos hacen constante mención de la Virgen, quien durante siglos ha sido la salvadora de la ciudad. Una virgen que en ocasiones de peligro deja a un lado al infante Jesús y empuña la espada, como una Palas Atenea. El fin de la tragedia se resuelve mediante un deus ex machina; no porque la Virgen logre salvar Constantinopla, sino porque los feligreses en Santa Sofía contemplan asombrados a la Virgen llevar en brazos a Constantino, convertido en una estatua de mármol, y a ambos desaparecer tras el muro del altar. El higúmeno exclama:

¡No lloren! A las profundidades de la tierra va la Virgen a dejarlo, como una semilla. Mil veces descendió ella al Hades y mil veces ha resucitado. Tiempo vendrá en que salga otra vez el sacerdote a la luz del sol para terminar la misa en la ciudad liberada.

Al final todos entonan un cántico, que es uno de los más conocidos trenos compuestos tras la caída de Constantinopla.

Hay que agradecer a Kazantzákis el haber introducido música en este drama, pues - como olvidan muchos estudiosos de la escena trágica y los teatristas - ni la tragedia ni la comedia podían prescindir del canto y de la danza. El autor no tuvo necesidad de componer la música (obligación que sí tenían sus lejanos antepasados): le bastó con elegir algunos cánticos que aún forman parte de la liturgia de la iglesia ortodoxa griega, los cuales provienen del inmenso caudal creado en la época bizantina.

Como es sabido, los escritores griegos modernos, y especialmente los poetas, siguen abrevando en las fuentes antiguas, sobre todo aquéllos con una apreciable cultura, como es el caso de Palamás y Seféris (premio Nobel de Literatura 1963). Giórgos Seféris suele poner notas explicativas cuando hace alusiones a textos clásicos, a fin de que ninguno de sus 
lectores pierda el significado. En su poemario Cuaderno de bitácora iii, se encuentra un poema llamado "Eurípides, el ateniense", que dice:

Concebía las venas de los hombres

como una red tendida por los dioses

para atraparnos en ella como fieras,

pero él se empeñó en destruir esa red.

Seféris no hace la aclaración, pero considero que se pudo haber basado en una escena de Las fenicias de Eurípides, cuando Polinices entra a la sitiada Tebas, a pedido de su madre, a fin de que intente llegar a un acuerdo con su hermano Eteocles y evitar la guerra. Polinices entra temeroso a la ciudad y, en su monólogo, dice: "Temo que me apresen dentro de unas redes y que no me dejen salir sin teñir mi cuerpo de sangre" (v. 264).

Los europeos califican a Grecia como "la cuna de la civilización", es decir, como si los frutos helenos hubiesen estado predestinados a llegar a Occidente; la verdad es que Grecia estuvo durante siglos insertada en la historia de los países del oriente del Mediterráneo, pues su naves comerciaban en las costas egipcias, palestinas y del Asia Menor. La cultura helena no sólo se diseminó en el amplio territorio conquistado por Alejandro Magno durante la época helenística y romana, aún sigue teniendo resonancia en nuestros días. Así vemos al poeta palestino Mahmud Darwish (n. 1941) escribir un poema intitulado "Escogemos a Sófocles", un trasunto de los horrores de lejanas batallas revividas ahora en un país despojado y sin futuro:

Si este otoño debía ser el último, entonces perdón por el flujo y el reflujo de los mares y de las memorias. Perdón por lo que hemos hecho con nuestros semejantes antes de la Edad del cobre; cuántas criaturas hemos herido 
con las armas talladas en los huesos de nuestros hermanos (...) Cuando se extendió un hilillo púrpura sobre el agua sin que notáramos que era nuestra sangre que recitaba nuestra marcha entre las anémonas de esos lugares tan hermosos. ${ }^{6}$

Pasemos ahora a una zona que nada tiene que ver con ese Occidente de cultura greco-romana: África; pero no la costa africana que comparte el Mediterráneo con Europa, sino a Nigeria. De este país proviene Wole Soyinka (Premio Nobel, 1986), quien tuvo parte de su educación en Inglaterra y escribe en inglés. Entre sus obras de teatro se encuentra una intitulada Las bacantes de Eurípides. Ritual de la comunidad. ${ }^{7}$ En una nota introductoria el autor señala:

Como mi conocimiento del griego clásico tiene veinte años de enmohecimiento, para esta adaptación de Las bacantes he debido apoyarme en traducciones anteriores. De dos versiones, la de Gilbert Murray y la de William Arrowsmith, he tomado frases y versos completos. También he de mencionar mi deuda con mi propio Idanre, un poema sobre la Pasión de Ogún, hermano mayor de Dioniso. De este extenso poema he introducido muchos versos, sobre todo para los cantos de alabanza (p. 234).

El hecho de que el autor se base en Eurípides no supone un zurcido al estilo de La Pasión de Cristo bizantina, sino que entreteje con gran maestría el texto griego con el propio, en un inglés fluido y nada arcaizante. Esta obra es muy extensa y compleja, lo cual impide ofrecer aquí un análisis completo; me limitaré a señalar algunas de sus más acusadas características, deteniéndome también en las acotaciones que Soyinka, consumado teatrista, ofrece con amplitud. La primera indicación se refiere a la escenografía:

\footnotetext{
${ }^{6}$ Traducido del árabe al francés por Jamel Eddine Bencheikh y del francés al español por David Huerta. Cfr. Letras Libres, 13, 2000, p. 68.

${ }^{7}$ Collected plays, vol. I, Oxford, Oxford University Press, 1973.
} 
A un costado, un camino conduce en declive hacia el fondo de la escena, bordeado por los cadáveres de esclavos crucificados casi reducidos a esqueletos. La procesión que llega después por este camino parece emerger de las entrañas de la tierra. La tumba de Semele, al otro costado, humea ligeramente. Al fondo, la puerta principal del palacio de Penteo.

Aquí se encuentran dos constantes del drama: la presencia del cristianismo ${ }^{8}$ y de la esclavitud. Una faceta oscura de la cultura griega fue el empleo de esclavos; sin embargo, es obvio que Soyinka no está haciendo sólo alusión a la Antigüedad clásica, sino al infame comercio de esclavos africanos llevado a cabo por los "civilizados" europeos y norteamericanos. En cuanto a los actores, se acota:

El elenco de los esclavos y las bacantes deberá ser tan mixto como sea posible, para atestiguar sus variados orígenes. Se sugiere que el jefe de los esclavos sea totalmente negroide. Dioniso debe tener una belleza agresiva, no una lindura afeminada.

Como en el original, Dioniso abre la tragedia con un monólogo. El dios griego menciona que ha estado en Lidia, Frigia, Bactria, Persia, Arabia y Asia, en tanto que el nigeriano añade Afganistán y la oscura Etiopía. A continuación debería estar la entrada del coro de bacantes, pero Soyinka introduce una muy larga escena en la que aparece, primero, un grupo de esclavos que trilla el grano. Un pastor (que les lleva vino) y el jefe de los esclavos dialogan; anuncian que se acerca una procesión que se dirige a Eleusis, para celebrar "unos ritos inefables" (unspeakable puede entenderse como secretos o execrables). Después, aparece el cortejo de sacerdotes vestidos de negro y vestales con túnicas blancas; tras ellos un

\footnotetext{
${ }^{8}$ Nigeria fue una colonia británica hasta 1960. Es uno de los países más populosos de África y sus habitantes son, en su gran mayoría, musulmanes, pero también hay cristianos y seguidores de las antiguas religiones.
} 
anciano de barba blanca vestido con arpillera y cuatro hombres de rojo que lo flagelan. Cuando el anciano cae rendido, un reflector ilumina a Dioniso junto a la tumba de Semele. Acotación: "Cesa toda acción y se escucha la música de Dioniso". A lo largo de la obra aparece varias veces la indicación "música de Dioniso", por lo tanto, hay un leitmotif dionisiaco que permea todo el drama. El dios dice: "Canten la muerte del Año Viejo y den la bienvenida al Nuevo... dios". Soyinka funde aquí dos ritos, el eleusino y el del cambio de año (o de rey): se despide al viejo, flagelando a una vícitma propiciatoria, a fin de que el nuevo llegue limpio de culpa. Los esclavos (que esperan ser liberados por este nuevo dios) y las vestales (no muy convencidas) acaban cantando y bailando en honor a Dioniso. Salen del escenario.

Quedan en la escena el anciano que representaba al Año Viejo, y que resulta ser Tiresias, más los cuatro flageladores. Aquél los increpa: “¡Bastardos! ¿Acaso no pueden entender la diferencia entre ritual y realidad? Flagelación simbólica, eso es lo que he tratado de hacer entrar en sus cabezotas". Cuando van saliendo les pregunta: “QQuién se ha quedado con mi bastón?" Dioniso se acerca a él y le dice: "Puedes tomar mi tirso". -Tiresias: "Gracias, eres Dioniso ¿verdad?" —Dioniso: "Ves demasiado bien, Tiresias". Los dos dialogan y al final el profeta confiesa que su único deseo es alcanzar el éxtasis. -Dioniso: "Entonces, danza para mí". Acotación: "Se escucha la música de Dioniso y Tiresias empieza a bailar, en un principio con torpeza, después logra seguir el ritmo y baila extasiado". Sale el dios y entra Cadmo.

El diálogo entre Cadmo y Tiresias constituye el Primer episodio de la tragedia de Eurípides y, de aquí en adelante, Soyinka seguirá el orden de ésta, aun cuando no separa formalmente las secciones de los actores y del coro, sino que las va mezclando en una acción continuada. Apenas han intercambiado saludos el rey y el profeta, cuando irrumpe el coro de las bacantes, en estado de frenesí, y después se le aúna el coro 
de esclavos (acotación: "con una música de cuerdas y panderos orientales", que termina en "gemidos orgásmicos como en un público de adolescentes de música pop"). Cuando se han ido los coreutas, Cadmo y Tiresias deciden partir a la montaña. Hasta aquí la obra tiene muchos elementos de comedia — sobre todo en este último diálogo — o quizá sería mejor decir que corresponde a ese género perdido: el drama satírico.

Una vez que entra Penteo y sostiene un agón con su padre y Tiresias, el texto se acerca más al de Eurípides; como en el primer agón entre Penteo y Dioniso, que abre el Episodio segundo. Cuando el rey ordena que el dios sea encadenado y llevado a prisión, Soyinka acota:

las bacantes inician un sonido, una forma de ulular propia de algunos pueblos orientales y africanos, que significa una gran angustia, agitación o un llamado de advertencia. Va subiendo de volumen, a medida que los esclavos se unen, hasta volverse ensordecedor.

Después de que Dioniso se ha liberado y ha hecho creer a Penteo que su palacio se incendió, éste escucha al mensajero narrar lo que sucede en el Citerón y decide ir con su ejército para aniquilar a las tebanas convertidas en bacantes. Dioniso trata de disuadirlo y, para lograrlo, Soyinka crea dos escenas ilusorias, que en el texto aparecen como acotaciones y no indica si hay actores que las representen o son imágenes proyectadas en una pantalla.

Como quiera que se las recree, la primera ilusión narra el desarrollo de una ceremonia de esponsales. La novia lleva una máscara de terrible fealdad, en tanto que el novio, desastrado, se dedica a beber. Dioniso contempla divertido la escena. El novio empieza a bailar con desenfreno; se quita máscara y vestimenta: debajo trae la piel de cervatillo de los orgiastas dionisíacos. El padre de la novia exclama: "Hipocleides, has perdido a tu esposa por causa de una danza", a lo que el novio 
responde: "A Hipocleides no le importa". Soyinka inventa la escena, pero - aunque no lo señala- las dos últimas frases provienen de Heródoto (Libro VI, cap. 126 y ss.). Las pronuncian Clístenes, tirano de Sición y ese tal Hipocleides, quien concursaba por ganar la mano de la princesa y falló al danzar con vulgaridad e impudencia.

La segunda ilusión es otra boda. En ella aparece la figura de Cristo sentado, con un halo que semeja la guirnalda de hiedra dionisíaca. Entra una mujer furiosa porque el vino se ha terminado, pero Cristo hace llenar cántaros con agua y los convierte en vino. Todos los asistentes lo prueban y quedan arrobados. Le sigue una tercera ilusión, esta sí euripidea, cuando Penteo cree ver dos ciudades de Tebas y a Dioniso convertido en toro. Finalmente el dios lo viste de mujer y el rey sale danzando hacia el Citerón.

La obra sigue su curso bastante apegada a la tragedia de Eurípides; sin embargo, el final es diferente: Dioniso ya no aparece para decir que cometieron el error fatal de no reconocerlo y para decretar que Cadmo y sus hijas serán castigados con el exilio. Quien sí regresa es Tiresias. Ágave sube a una escalera y, con sus propias manos, clava la cabeza "del león" en la fachada del palacio. En la última acotación Soyinka describe el final: "Empieza el tema musical de Dioniso. Un poderoso brillo rojo surge de la cabeza de Penteo; de repente, de cada orificio de ésta surgen chorros de un líquido rojo. Reacciones de horror y pánico". Tiresias pregunta: "Cadmo, ¿qué es esto?" - Cadmo: "Sangre, Tiresias, todo es sangre". Tiresias prueba el líquido en el cuenco de su mano y exclama: "No, es vino". Todos, incluso Ágave, se acercan a beber este don dionisíaco.

El final, sobre todo si es visto en escena, puede resultar algo grotesco y desagradable; no obstante, concuerda con la visión que Soyinka, en varias de sus obras, tiene sobre la religión en general: los dioses se desentienden de las desgracias humanas, los sacerdotes manipulan la fe en provecho propio y los segui- 
dores son unos crédulos enajenados por meras ilusiones. La obra es excelente, tiene una vitalidad que no suele encontrarse en las representaciones del repertorio clásico.

Por último, nos trasladaremos a una zona en el Nuevo Mundo: Latinoamérica; si bien pertenece en gran medida a la cultura de Occidente, su prolongado estar en "vías de desarrollo" la mantiene en un sitio marginal. En México, Alfonso Reyes — conforme a su acusada helenofilia- escribió en 1923 un "poema dramático" denominado Ifigenia cruel, ${ }^{9}$ basado en la Ifigenia en Táuride de Eurípides. La trama es idéntica, lo que cambia es el destino final. El autor explica así sus razones.

Supongo aquí que Ifigenia, arrebatada en Áulide por la diosa Artemisa a las manos del sacrificador, ha olvidado ya su vida primera e ignora cómo ha venido a ser, en Táuride, sacerdotisa del culto bárbaro y cruel de su divinidad protectora. El conflicto trágico consiste para mí, precisamente, en que Ifigenia reclama su herencia de recuerdos humanos y tiene miedo de sentirse huérfana de pasado y distinta de las demás criaturas; pero cuando más tarde vuelve a ella la memoria y se percata de que pertenece a una raza ensangrentada y perseguida por la maldición de los dioses, entonces siente asco de sí misma. Ante la alternativa de reincorporarse a la tradición de su casa o de seguir viviendo entre bárbaros, prefiere este último extremo, por abominable y duro que parezca (p. 313).

La obra es muy breve y no tiene atractivo escénico; es más bien teatro para ser leído y su verdadero valor es el gran aliento poético que posee. Nos hace lamentar que gran parte de las traducciones del repertorio clásico carezca de cualidades poéticas. Es cierto que más vale una buena prosa que una mala versificación (T. S. Eliot en su "Eurípides y el Profesor

9 Obras completas de Alfonso Reyes, vol. X. Constancia poética, México, Fondo de Cultura Económica, 1959. 
Murray"10 hace una crítica devastadora de la traducción que éste hace de Medea: lo acusa de ser arcaizante, de distorsionar el original e introducir muchas palabras de su cosecha con tal de lograr una versión poética rimada); sin embargo, los grandes pasajes líricos — sobre todo los de Esquilo- se convierten en prosa en un débil trasunto del original. Reyes, en cambio, nos gratifica con una obra plena de ritmo. Unos cuantos ejemplos bastarán para comprobarlo:

Ifigenia inicia la obra con las siguientes palabras:

Ay de mí, que nazco sin madre y ando recelosa de mí, acechando el ruido de mis plantas por si adivino adónde voy. Porque un día, al despegar los párpados, me eché a llorar, sintiendo que vivía; y comenzó este miedo largo, este alentar de un animal ajeno entre un bosque, un templo y el mar.

El coro de mujeres de Táuride:

Respetemos el dolor de la que salió de la muerte y brotó como un hongo en las rocas del templo. Yo te envidio, señora, el agrio gusto de ignorar tu historia.

Así es como el coro anuncia la llegada del mensajero:

Pero callemos, que un pastor color de tierra, vago engendro de lanas y hojarasca

se acerca aquí (...)

filtrando una mirada de ansia y susto.

10 The Sacred Wood. Essays on Poetry and Criticism, London, Methuen, 1948, pp. 71-77. 
Reyes señala que "en las versiones de la tragedia ateniense, Orestes e Ifigenia saben bien quiénes son y simplemente se reconocen el uno al otro. En mi interpretación, Ifigenia se ignora, y sólo se identifica a sí misma al reconocer a Orestes". En el pasaje de la anagnórisis, Ifigenia dice a su hermano:

Calla, porque me aniquila el peso del nombre que espero; oh vencedor extraño, calla, porque al fin no quiero Orestes: saber —oh cobarde seno- quién soy yo.

¿Diré, Pílades, el nombre que azuce las bandadas de nombres temerosas? (...) habré de conducirla paso a paso, como a ciega extraviada que tantea el camino, hasta dejarla donde la perdí.

A Ifigenia:

Te asiré del ombligo del recuerdo; te ataré al centro del que parte tu alma. Apenas llego a ser tu prisionero, cuando eres ya mi esclava.

Ifigenia al coro:

Amigas, huyo: jesto es el recuerdo!

Huyo, porque me siento cogida por cien crímenes al suelo. Huyo de mi recuerdo y de mi historia, como yegua que intenta salirse de su sombra.

Una vez que Ifigenia recuerda lo sucedido en Áulide y Orestes le informa que ha venido a rescatarla, ella se niega a partir; él le dice:

¿Y qué harás, insensata, para quebrar las sílabas del nombre que padeces? Ifigenia:

Robarás una voz, rescatarás un eco; un arrepentimiento, no un deseo. Llévate entre las manos, cogidas con tu ingenio, estas dos conchas huecas de palabras: ¡No quiero! Refúgiase en el templo, desapareciendo de la escena. 
El coro canta al final:
Alta señora cruel y pura:
compénsate a ti misma, incomparable; (...)
escoge el nombre que te guste
y llámate a ti misma como quieras:
ya abriste pausa en los destinos, donde
brinca la fuente de tu libertad.

Oscar Wilde, ese incansable creador de aforismos, dijo que "las traducciones son la literatura de los ecos". En el caso de la dramaturgia griega estamos ante un doble eco. El primero sería el traslado del original griego a una lengua contemporánea, en un texto donde en un estudio preliminar y notas sea posible añadir todas las explicaciones e interpretaciones que el filólogo juzgue convenientes. El segundo eco sería traducir la tragedia como lo que verdaderamente es: un libreto teatral que va a cobrar vida en un escenario. El traductor sin oído para su propia lengua y desconocedor del lenguaje escénico será incapaz de producir eco alguno. Entre los variados ejemplos que es dable encontrar en muchas lenguas, he aquí uno de cierta traducción española del Edipo de Eurípides: cuando Yocasta hace su entrada en escena explica la razón por la cual el rey, su marido, y ella se vieron obligados a deshacerse de su hijo, y pronuncia lo siguiente: "Vínole a Layo un oráculo". La actriz puede sufrir un tropiezo de dicción ante el segmento -ínole a Lay_, por otra parte, todo traductor debería saber que al final de verso no hay que situar una palabra con terminación malsonante o de doble sentido; a menos que desee convertir una tragedia en una hilarante comedia.

Volviendo a Alfonso Reyes. En el prólogo a su versión poética de $L a$ Ilíada, ${ }^{11}$ acepta con sinceridad: "No leo la lengua de Homero, la descifro apenas". Si bien su conoci-

\footnotetext{
${ }^{11}$ La Ilíada de Homero, trasl. Alfonso Reyes, México, Fondo de Cultura Económica, 1951.
} 
miento del griego no rebasaba la medianía, su comprensión de la literatura era la de un literato, y en eso aventajaba a bastantes filólogos. Añade que

la fidelidad ha de ser de obra y no de palabra (...) Malo, muy malo, si se cae en la manía etimológica, que ya está dando resultados funestos y falsea la representación que los mismos griegos tenían de sus vocablos; nadie se pone a la sombra de una semilla, sino de un árbol (p. 7).

Siguiendo con la metáfora arbórea de Reyes, vemos que las semillas que hace tanto tiempo plantaron los dramaturgos griegos han continuado produciendo variados frutos, incluso en lugares insospechados. El poeta griego contemporáneo Yánnis Rítsos abona sobre el terreno en "Disolución":

A veces las palabras brotan solas, como las hojas en los árboles... seguramente las raíces —invisiblesla tierra, el sol, el agua han ayudado, como ayudaron las hojas podridas del pasado. 